\title{
Assessing the magnitude and uncertainties of the burden of selected diseases attributable to extreme heat and extreme precipitation under a climate change scenario in Michigan for the period 2041-2070
}

Carina J. Gronlund ${ }^{1 *} \mathbb{D}$, Lorraine Cameron ${ }^{2}$, Claire Shea ${ }^{2}$ and Marie S. O'Neill ${ }^{3}$

\begin{abstract}
Background: Extreme heat $(E H)$ and extreme precipitation (EP) events are expected to increase with climate change in many parts of the world. Characterizing the potential future morbidity and mortality burden of EH and EP and associated costs, as well as uncertainties in the estimates, can identify areas for public health intervention and inform adaptation strategies. We demonstrate a burden of disease and uncertainty assessment using data from Michigan, USA, and provide approaches for deriving these estimates for locations lacking certain data inputs.

Methods: Case-crossover analysis adapted from previous Michigan-specific modeling was used to characterize the historical EH-mortality relationship by county poverty rate and age group. Historical EH-associated hospitalization and emergency room visit risks from the literature were adapted to Michigan. In the U.S. Environmental Protection Agency's BenMAP software, we used a novel approach, with multiple spatiallyvarying exposures, to estimate all non-accidental mortality and morbidity occurring on EH days (EH days; days where maximum temperature 32.2-35 C or > 35 C) and EP days. We did so for two time periods: the "historical" period (1971-2000), and the "projected" period (2041-2070), by county.

Results: The rate of all non-accidental mortality associated with $\mathrm{EH}$ days increased from $0.46 / 100,000$ persons historically to $2.9 / 100,000$ in the projected period, for 240 EH-attributable deaths annually. EH-associated ED visits increased from 12/100,000 persons to 68/100,000 persons, for $7800 \mathrm{EH}$-attributable emergency department visits. EP-associated ED visits increased minimally from 1.7 to 1.9/100,000 persons. Mortality and morbidity were highest among those aged $65+$ (91\% of all deaths). Projected health costs are dominated by EH-associated mortality ( $\$ 280$ million) and EH-associated emergency department visits ( $\$ 14$ million). A variety of sources contribute to a moderate-to-high degree of uncertainty around the point estimates, including uncertainty in the magnitude of climate change, population composition, baseline health rates, and exposureresponse estimates.

(Continued on next page)
\end{abstract}

* Correspondence: gronlund@umich.edu

${ }^{1}$ Center for Social Epidemiology and Population Health, University of

Michigan School of Public Health, 1415 Washington Heights, Ann Arbor, MI

48109-2029, USA

Full list of author information is available at the end of the article

(c) The Author(s). 2019 Open Access This article is distributed under the terms of the Creative Commons Attribution 4.0 International License (http://creativecommons.org/licenses/by/4.0/), which permits unrestricted use, distribution, and reproduction in any medium, provided you give appropriate credit to the original author(s) and the source, provide a link to the Creative Commons license, and indicate if changes were made. The Creative Commons Public Domain Dedication waiver (http://creativecommons.org/publicdomain/zero/1.0/) applies to the data made available in this article, unless otherwise stated. 
(Continued from previous page)

Conclusions: The approach applied here showed that health burden due to climate may significantly rise for all Michigan counties by midcentury. The costs to health care and uncertainties in the estimates, given the potential for substantial attributable burden, provide additional information to guide adaptation measures for EH and EP.

Keywords: Climate change, Morbidity, Mortality, Emergency department, Hospitalization, Extreme heat, Extreme precipitation

\section{Background}

In this changing climate, state and local health departments in the USA and elsewhere are considering how best to protect the public's health. Approaches to estimate future burden of disease of climate-related health outcomes and the associated costs and uncertainties can guide planning and fiscal policy. Detailed examples of how these approaches can be applied in a specific place--in this case, Michigan, USA--offer a template for their use elsewhere.

During a strategic planning initiative in 2010, the Michigan Department of Health and Human Services Climate and Health Adaptation Program identified specific health outcomes as priority concerns when considering the impacts from climate change in Michigan [1], including but not limited to heat-related illnesses and waterborne diseases. These effects were chosen based on evidence that Michigan-specific climate change effects include increases in $\mathrm{EH}$ events and increases in extreme precipitation (EP) events and concomitant flooding events $[2,3]$.

Following this scoping phase, we estimated the present and future burden of disease associated with these health outcomes. We followed the U.S. Centers for Disease Control and Prevention technical guidance for health departments for projecting climate-related disease burden [4] by, 1) developing a causal pathway linking exposures/environmental hazards to health outcomes, 2) using ensemble projections from global climate models (GCMs) to identify how the exposures/environmental hazards may change in intensity and duration in the future, 3) establishing the historical disease burdens of the health outcomes in our populations, 4) assessing the historical exposure-outcome associations, 5) estimating the health burdens historically and in the projected climate, and then 6) evaluating the uncertainty inherent in the derivation of these different estimates.. The results will help prioritize county level measures to better protect public health in a changing climate. We also present our methods as a model to other states and municipalities, including methods for deriving baseline health data and exposure-response estimates when these are lacking.

\section{Methods}

An overview of the methods is provided below and summarized in Fig. 1 and Table 1. Additional details sufficient to replicate the analyses are provided in Additional file 1: Appendix 1.

\section{Review of causal pathways}

For the priority health outcomes, we reviewed the literature concerning EH-associated mortality, EH-associated hospitalizations, EH-associated emergency department (ED) visits, EP-associated gastrointestinal (GI) illness, and EP-associated respiratory illness. We focused specifically on studies including Michigan residents, and in the absence of such studies, we selected studies of U.S. populations in climates similar to that of Michigan. Based on the availability of studies and their quality, we chose whether to perform quantitative estimates of disease burden for a given exposure-outcome association or to assess the burden qualitatively.

\section{Multi-GCM ensemble projections \\ EH}

The mean annual number of days with maximum temperatures above $32.2^{\circ} \mathrm{C}$ and above $35^{\circ} \mathrm{C}$, or $\mathrm{EH}$ days, were obtained for two time periods: 1971-2000 (historical) and 2041-2070 (projected) from the Great Lakes Integrated Sciences + Assessments Center [5]. These were derived under the Intergovernmental Panel on Climate Change A2 scenario, which is one of the more dire scenarios and assumes greenhouse gas concentrations will continue to increase throughout the twenty-first century [2]. The historical EH data are the Maurer 1/ 8 -degree gridded daily maximum temperature observations [6]. The projections were statistically-downscaled data sets from the North American Regional Climate Change Assessment Program [3] derived from Climate Model Intercomparison Project Phase 3 GCMs. Estimates of $\mathrm{EH}$ days were provided at a $1 / 8^{\circ}$ grid resolution and were aggregated to match the spatial resolution of the health data (see Additional file 1: Appendix 2 for aggregation details).

No universal definition of EH exists, and the thresholds of $32.2^{\circ} \mathrm{C}$ and $35^{\circ} \mathrm{C}$ were chosen for two reasons. Firstly, these correspond to round Fahrenheit temperatures of $90^{\circ} \mathrm{F}$ and $95^{\circ} \mathrm{F}$, and extreme caution is advised by the local Detroit National Weather Service office at temperatures over $90^{\circ} \mathrm{F}$ [7]. Although these were well above the minimum-mortality-temperature thresholds of 


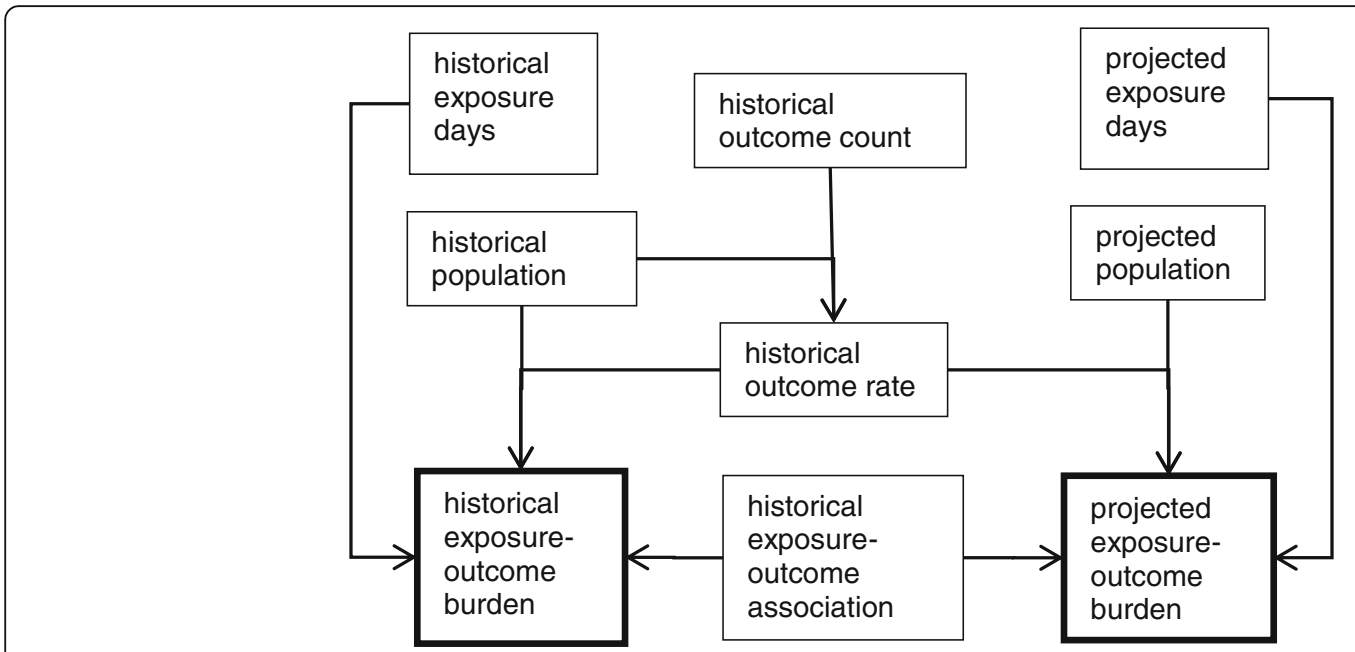

Fig. 1 Steps in burden-of-disease estimates for outcomes of mortality, hospitalization and emergency department (ED) visits for the extreme heat (EH) exposure and the outcome of gastrointestinal (GI) ED visits for the extreme precipitation (EP) exposure. See Table 1 for data sources

21-24 ${ }^{\circ} \mathrm{C}$ identified in Gasparrini et al. [8] for cities in Michigan, the $32.2^{\circ} \mathrm{C}$ threshold corresponds roughly to a Detroit heat-mortality threshold in Gronlund et al. [9], which used more recent, albeit more spatially constrained, mortality time series. Secondly, time series and case-crossover study designs, on which our estimates are based, can account for mortality displacements of 1-3 weeks, thereby subtracting out the mortality attributable to heat that was among very frail individuals who would have died within 1-3 weeks anyway. Beyond 3 weeks, we are not aware of research quantifying mortality displacement specific to cities in Michigan, although the extent of mortality displacement varies widely between countries [10]. The literature is inconclusive, but there is

Table 1 Source of data for each step (Fig. 1) in the burden of disease calculation and years of data used

\begin{tabular}{|c|c|c|c|}
\hline Step & Data Source & Historical & Projected \\
\hline Extreme heat $(\mathrm{EH})$ days & $\begin{array}{l}\text { Maurer 1/8-degree gridded daily maximum } \\
\text { temperature observations [6] }\end{array}$ & $1971-2000$ & \\
\hline Extreme heat (EH) days & $\begin{array}{l}\text { Multi-model ensemble }{ }^{\mathrm{b}} \text { of statistically-downscaled } \\
\text { 1/8-degree dailydata sets from the North American } \\
\text { Regional Climate Change Assessment Program [3] }\end{array}$ & & $2041-2070$ \\
\hline Extreme precipitation (EP) days & $\begin{array}{l}\text { Multi-model ensemble }{ }^{b} \text { of statistically-downscaled } \\
\text { 1/8-degree daily projections }[3,5,14,15]\end{array}$ & $1971-2000^{a}$ & $2041-2070$ \\
\hline Population & U.S. Census [16] & $1971-2000$ & \\
\hline Population & Woods \& Poole economic forecasting model [17] & & 2050 \\
\hline Population & $\begin{array}{l}\text { EPA's Integrated Climate and Land-Use Scenarios } \\
\text { (ICLUS) project for the A2 scenario }[16,103]\end{array}$ & & 2050 \\
\hline All-natural-cause mortality & $\begin{array}{l}\text { Centers for Disease Control (CDC), National Center } \\
\text { for Health Statistics (NCHS) [17] }\end{array}$ & 2004-2006 & \\
\hline Renal/respiratory/heat hospitalizations, ages 65+ & Medicare MedPAR billing records [20] & 1990-2006 & \\
\hline Renal hospitalizations, ages 0-64 & Michigan Inpatient Database [18] & 2000-2009 & \\
\hline $\begin{array}{l}\text { All-natural-cause and gastrointestinal emergency } \\
\text { department (ED) visits }\end{array}$ & $\begin{array}{l}\text { Healthcare Cost and Utilization Project, Agency for } \\
\text { Healthcare Research and Quality [21] }\end{array}$ & 2007 & \\
\hline EH-mortality association & case-crossover analysis, see Methods & & \\
\hline EH-renal/respiratory/heat hospitalization association & Ogbomo et al. [18] & 2000-2009 & \\
\hline EH-renal hospitalization association & Gronlund et al. [20] & 1990-2006 & \\
\hline EH-all-natural-cause ED visit association & Kingsley et al. [25] & 1999-2011 & \\
\hline EP-GI ED visit association & Jagai et al. [27] & 2003-2007 & \\
\hline
\end{tabular}

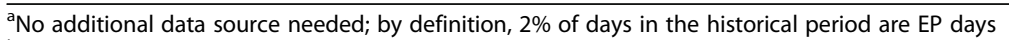

berived from the following six Climate Model Intercomparison Project Phase 3 global climate models (GCMs): cgcm3_t47, cgcm3_t63, cnrm, echam5, gfdl_2.1, pcm 
some suspicion that this mortality displacement is reduced at very high temperatures [11-13]. Therefore, in using high $\mathrm{EH}$ thresholds, we have greater confidence in assigning years, rather than weeks, of life lost to $\mathrm{EH}$.

\section{EP}

Based on an ensemble of downscaled daily climate projections $[3,5,14,15]$ (Table 1) for the A2 scenario, EP events (the heaviest $2 \%$ of precipitation events in a given area) are projected to increase in Michigan between an additional 0.5 days to over 2.0 days per year.

\section{Historical disease burden of the health outcomes Mortality rates}

The U.S. Environmental Protection Agency's (EPA) Environmental Benefits Mapping and Analysis Program (BenMAP) is a free, geographic information system (GIS)-based software that calculates and maps the health impacts associated with changes in air quality or temperature [16]. The BenMAP software contains past and present age-, cause-, and county-specific mortality rates derived from National Center for Health Statistics and U.S. Census data [17].

\section{Hospitalization rates}

BenMAP does not include information on renal or heat-related (i.e., specific effects of heat such as heat exhaustion and heat stroke) hospitalization rates. Therefore, annual warm season (May-September) renal hospitalization rates were estimated from a Michigan study of EH and hospitalization for individuals 0-64 years of age [18] in conjunction with U.S. Census data [19]. For individuals 65 years and older, hospitalizations for renal, respiratory and heat causes were derived from a study of $\mathrm{EH}$ and hospitalization, which included Michigan [20].

\section{ED rates}

Because Michigan does not provide state or discharge-level data on ED visits, Michigan-specific ED visit rates for heat-related and non-accidental causes were estimated using Healthcare Cost and Utilization Project (HCUP) data [21] from the Midwest region and applied to all Michigan counties. See Section 6 for Results regarding the variation in ED visit rates among states in the Midwest and Additional file 1: Appendix 3 for detailed Methods and Results.

\section{Population counts}

Historical population data from the 2000 U.S. Census [16] were available in BenMAP. We used 2050 population projections from EPA's Integrated Climate and Land-Use Scenarios (ICLUS) project for the A2 scenario. ICLUS population projections are based on the
2000-2005 U.S. Census population, fertility, and mortality rates by age, sex, and race to project county-specific populations out to 2100 [22]. For the A2 scenario, the resulting ICLUS population includes an assumption of higher fertility rates. As a sensitivity analysis, we used BenMAP's pre-loaded Woods \& Poole 2050 projections.

\section{Historical exposure-outcome associations \\ EH-mortality association}

Land cover by heat-retaining surfaces, minority racial status, and low socioeconomic status have been found in previous research to increase vulnerability to $\mathrm{EH}$ [23]. To estimate the EH-mortality association, we performed a new epidemiologic analysis based on a recent Michigan-specific analysis by Gronlund et al. [9] using Michigan mortality records, airport temperature data, and ZIP-code level estimates of green space, percent of residents of black race, percent of individuals 65 years and older and living alone, and percent below the poverty level. Based on the previous analysis suggesting a great reduction or absence of an EH-mortality association beyond 3 days after the $\mathrm{EH}$ exposure in this region, we restricted the analysis to the day of through 3 days following the EH exposure. We updated the analysis to use an $\mathrm{EH}$ definition that precisely matched that in the available climate projections and to include all ages. Attributable fractions (AFs), or the fraction of deaths attributable to 1 day of $\mathrm{EH}$, were calculated for each ZIP code, age group and $\mathrm{EH}$ threshold $\left(32.2\right.$ or $\left.35^{\circ} \mathrm{C}\right)$ based on the derived risk ratios (RRs). Race was not found to be a significant modifier of the EH-mortality association when land cover and socioeconomic characteristics were accounted for. Although green space was found to significantly modify the EH-mortality association, it was not included in the AF estimate due to the fact that green space was a variable used in estimating the number of historical and projected EH days.

\section{EH-hospitalization association}

Strong associations between EH and renal-cause hospitalizations have been found in several U.S. studies [24], as has significant effect modification by white vs. black race among individuals 65 and older in the U.S. [20]. From a Michigan-specific study by Ogbomo et al. [18], we estimated an AF for individuals under 65 years of age at a same-day $\mathrm{EH}$ threshold of $32.2{ }^{\circ} \mathrm{C}$. Renal effects for 2-, 3-, and 4-day long $\mathrm{EH}$ events were similar to same-day EH effects, and Ogbomo et al. only estimated effects by age group for same-day EH events. For individuals 65 years of age and older, we used the air conditioning prevalence region 2 (which included Michigan) ZIP-code specific AFs for six-day cumulative effects of $\mathrm{EH}$ at $32.2^{\circ} \mathrm{C}$ from the U.S. study of effect modification 
of renal, respiratory and heat-related hospitalizations by Gronlund et al. [20].

\section{$E H-E D$ visit association}

Exposure-response functions were derived from a study examining the effects of heat on morbidity and mortality by Kingsley et al. in Rhode Island [25], a state with a climate similar to that of Michigan's, i.e., cold and lacking a dry season and hot summers (Dfa, Dfb) in the Köppen climate classification system [26]. AFs for all-natural-cause ED visits for $\mathrm{EH}$ at $32.2{ }^{\circ} \mathrm{C}$ and $35^{\circ} \mathrm{C}$ were estimated for the $0-18$ age group and the 65 and older age group based on effect estimates of same-day maximum temperature and all-natural cause visits. In contrast to the mortality and hospitalization studies, Kingsley et al. did not estimate effects of temperature on $\mathrm{ED}$ visits on days following the $\mathrm{EH}$ exposure ${ }^{\circ} \mathrm{s}$. The association between same-day maximum temperature and all-natural-cause ED visits was not significant in the 18-64 age group. However, associations between heat-related ED visits and warm temperatures were strong in this age group; so heat-related AFs for $32.2^{\circ} \mathrm{C}$ and $35^{\circ} \mathrm{C}$ were estimated for $18-64$ year-olds.

\section{EP-ED visit association}

The exposure-response function was derived from a study by Jagai et al. examining the association between EP and GI illness in areas with and without combined-sewer overflows (CSOs) in Massachusetts [27]. The study was chosen due to its similar climate [26] as well as stratification by region according to the impact of CSOs: regions where the CSOs impacted drinking water sources, regions where the CSOs impacted recreational waters, and regions without CSOs. Such stratification was recommended in a recent review of 24 studies of the association between EP and waterborne infections [28].

\section{Historical and projected EH- and EP-attributable health burdens \\ Attributable burden counts}

For each time period $p$ (historical vs. projected), county $c$, age group $a$, race category $r$, and threshold $t\left(32.2-34.9{ }^{\circ} \mathrm{C}\right.$ or $\geq 35^{\circ} \mathrm{C}$ for $\mathrm{EH}$ and historical $2 \%$ heaviest rainfall amount for EP), we calculated the attributable fraction days $\left(A F D_{\text {cartp }}\right)$ as the product of the $A F_{\text {cart }}$ and the number of EH or EP days in that time period $\left(E H D_{p}\right) . A F D_{\text {carp }}$ was then calculated as the sum of the two $A F D_{\text {cartp }}$ values, one from each threshold. For mortality and hospitalization estimates, we first calculated AFD by ZIP code $z$ instead of county, and then we calculated $A F D_{\text {carp }}$ as the weighted average of the $A F D_{\text {zarp }}$ in that county, where the weights were the number of cases in that ZIP code and age-race group (Additional file 1: Appendix 4). For all health outcomes, the burden-of-disease function was then defined in BenMAP as

$$
B O D_{\text {carp }}=A F D_{\text {carp }} \times I R_{\text {carp }} \times P O P_{\text {carp }} \times \mathrm{C}
$$

where $B O D_{\text {carp }}$ was the burden of disease due to $\mathrm{EH}$ or EP in county $c$ in age group $a$ and race group $r$ in time period $p$ (historical or projected), $I R$ was the county-level (or state-level for ED visits) daily incidence rate, $P O P$ was the population, and $C$ scaled the incidence rate (for $\mathrm{EH}$ estimates only) from a daily annual to daily summer level, given reduced incidence in the summer vs. winter $(0.66$ for emergencydepartment visits and 0.39 for mortality). Of note, these BOD estimates assume that the entire population was exposed, or in a region experiencing that number of $\mathrm{EH}$ or EP days. The $B O D_{\text {carp }}$ estimates were then summed across age-race groups to generate the county and time-period-specific estimates. County estimates were summed to generate the statewide estimates. For EP, because neither our exposures nor our exposure-response functions varied geographically, we did not use BenMAP, and $B O D$ was estimated for the state as a whole for residents with drinking water from surface water sources.

\section{Attributable monetary costs}

To estimate the monetary statewide costs of the attributable burdens of each disease, we multiplied the period-specific statewide BOD estimates by the per-incident cost of death, renal hospitalization among whites and non-whites, non-accidental ED visit, or GI illness ED visit. The mortality incident cost was the dollars per quality-adjusted life-year (QALY) estimated in an incremental cost-effectiveness ratio analysis of current dialysis practices relative to less-costly alternatives [29]. Dialysis is often used as a benchmark of an amount that is justifiably paid to improve quality-adjusted life years and therefore a reasonable proxy of the value of a year of life [29]. To estimate the cost of heat-associated hospitalization associated with $\mathrm{EH}$, we used a cost of $\$ 5400$, with additional costs of $\$ 1500$ for individuals $65-77$ and $\$ 1600$ for individuals 78 and older from a study of hospitalization costs due to heat-related illness [30]. For respiratory and renal hospitalization costs, we used Healthcare Cost and Utilization Project 2014 Michigan data by age group [21]. To estimate ED visit costs, we calculated the median costs of non-accidental and gastrointestinal ED visits in the U.S. from the 2015 Medical Expenditure Panel Survey [31]. All cost results are given in 2010-2015 U.S. dollars, with no adjustment for inflation in the projected period. 


\section{Uncertainties}

Rather than attempt to assign precise quantitative ranges to the burden-of-disease inputs, we took a qualitative approach. To each source of uncertainty, we assigned values of "low," "moderate," or "high," defined as approximate ranges around the point estimates of $\pm 49 \%$ for low, $-99 \%$ to $-50 \%$ or $+50 \%$ to + $199 \%$ for moderate, and $-100 \%$ or $\geq+200 \%$ for high. This simple scale represents the idea that ranges of effects within half-as-much above or below the point estimate reflect low uncertainty, ranges that include null or protective effects (more than 100\% below) or effects more than three times as high reflect high uncertainty, and other ranges reflect moderate uncertainty. We drew on quantitative information when assigning these values, but we discuss additional uncertainties where present.

In order to evaluate uncertainty in population growth and distribution patterns, BOD estimates generated in BenMAP using the 2050 ICLUS population data for the A2 scenario were compared to the results derived using 2050 Woods \& Poole data [17]. The Woods \& Poole population projections are based on an economic forecasting model [32] while the ICLUS project used a demographic model with migration rates consistent with the IPCC's A2 scenario [33].

In generating the $\mathrm{EH}$ and $\mathrm{EP}$ day projections, Hayhoe et al. [15] did a bias analysis of each of the GCMs used to generate the "ensemble" mean projection for the US. In short, this analysis was accomplished by comparing the EH or EP days for the period 1960-1999 predicted by the models to those that actually occurred in that period. We reviewed the bias analyses relevant to the GCMs used to generate our historical and projected number of $\mathrm{EH}$ and EP days. We regard these as rough estimates of the bias in generating the A2 projection.

We also evaluated uncertainty in the exposure-response association and the baseline estimates of the health effects themselves, considering differences between studies of similar outcomes and changes in the health effect rates over time. To evaluate the uncertainties in the cost estimate of mortality, we used the estimated 1st and 99th percentiles of the dollar-per-QALY estimate [29]. For hospitalizations, we considered the $95 \%$ confidence intervals around estimated heat-related illness hospitalization costs [30]. For ED visits, we examined the first and third quartiles of the non-accidental and infectious intestinal illness visit costs estimated from the 2015 Medical Expenditure Panel Survey [31]. Using estimates of renal hospitalization counts [21] and annual population estimates [34], we compared age-adjusted renal hospitalization rates in 2001-2003 and 2012-2014. We also considered trends in ED visit rates from 2006 to 2011 [35].

\section{Results}

Review of causal pathways

$E H$

As part of the Climate and Health Profile Report, several direct and indirect health impacts related to EH and EP were identified [1]. Pathways by which EH affects health are direct and have been reviewed elsewhere [24, 36-38]. Briefly, mortality due to non-accidental causes was chosen as an indicator of disease burden for this analysis due to its known direct and immediate association with EH events [36, 37]. Non-accidental-cause ED visits and renal, respiratory and heat-related hospitalizations were chosen to best reflect the impact of $\mathrm{EH}$ on a wide variety of chronic diseases. Previous studies have shown associations between EH events and non-accidental-cause ED visits [38] and between EH and renal, respiratory and heat hospitalizations [24, 38]. Therefore, we included non-accidental cause mortality; renal, respiratory, and heat-related hospitalizations; and non-accidental ED visits in our EH burden of disease estimates, using studies that included Michigan and provided region-specific results, where possible, and from similar climates otherwise.

\section{EP}

Multiple pathways between EP and health may exist, although we did not find sufficient quantitative estimates of EP and health for the majority of these pathways to sufficiently characterize the health effects in our quantitative burden of disease estimates. Therefore, we describe these pathways in detail below. EP leads to contamination of surface water by increasing turbidity, by increasing the chances of harmful algal blooms, which are fed by agricultural run-off, and by prompting combined sewer overflows (CSOs). EP may also contaminate surface water when EP leads to flooding and flood waters wash contaminants into the surface water body.

EP events have been found to be associated with GI illness in countries outside the U.S. with inadequate treatment of public drinking water [39, 40]. Even in the U.S. where public water supplies are treated, a small proportion of illness has been attributed to waterborne disease [41]. These waterborne infections are caused by a variety of viruses, bacteria and protozoa. Though rare in Canada and the U.S., EP has been associated with waterborne disease outbreaks in recent decades: a Cryptosporidium outbreak in Milwaukee in 1993 and an Escherichia coli outbreak in Walkerton, Ontario in 2000 [42].

In addition to GI illnesses, a small number of studies have found an association between precipitation and the respiratory pathogen Legionella, or Legionnaires' disease in its most severe form, which thrives in warm water [43, 44]. In a study of legionellosis incidence in five 
Mid-Atlantic states from 1990 to 2003, Hicks et al. [45] found both monthly temperature (another meteorological variable predicted to increase with climate change) and rainfall to be associated with legionellosis. Specifically, Hicks et al. found a $2.6 \%$ increased risk of legionellosis with each $1-\mathrm{cm}$ increase in rainfall. A study in Switzerland did not find associations between precipitation and legionellosis, although the researchers did find associations of legionellosis with temperature and water vapor pressure [46]. A case-crossover study of 240 Legionella cases in the Philadelphia area from 1995 to 2003 also did not provide evidence of an association between precipitation and legionellosis when controlling for other meteorologic factors, but the researchers did find associations between Legionella and relative humidity, with RRs of 3.93 (95\% Confidence Interval: 2.18-7.09) and 3.59 (95\% CI: 2.06-6.28) for the 4th and 5 th quintiles of relative humidity, respectively, vs. the first quintile of relative humidity [47].

Turbidity, or water clarity, is often used as a proxy for microbial contamination, and the EPA has established regulations limiting levels of turbidity in public drinking water [48]. EP events can increase the turbidity in surface water. However, all drinking water treatment plants in Michigan actively reduce levels of turbidity when processing raw water into finished drinking water. Studies of associations between gastrointestinal illness and turbidity, at levels as low as those measured in U.S. drinking water systems, have shown mixed results. Studies in Philadelphia, Milwaukee, Atlanta, New York City, Vancouver, and Quebec each found associations between turbidity, as measured at the treatment plant, and GI illness in subsets of age groups, subsets of seasons and/or subsets of days following the elevated turbidity, [49-51]. However, a study in Edmonton failed to find any association between turbidity and GI illness [51].

Evidence is strong for associations between GI health effects and toxins produced by cyanobacteria in harmful algal blooms (HABs) [52]. The World Health Organization has set standards for microcystin levels in public drinking water systems [52], and these levels were exceeded in the 2014 Lake Erie algal bloom in Toledo, Ohio [53]. Almost 100,000 Michigan residents use public water systems with intakes in Lake Erie. The potential health effects of HABs in these cities are of concern given that current water treatment methods do not remove all of the toxins produced by the cyanobacteria. Emergency response plans addressing a $\mathrm{HAB}$, including bottled water distribution, have been put in place [53].

CSOs contaminate the receiving water with raw sewage and therefore with human pathogens. CSOs can lead to increased concentrations of pathogens in surface water [54-57]. Although treatment of the public water supply should remove these pathogens, a study in
Massachusetts found associations between EP and GI illness in regions in which the public drinking water came from surface water and CSO discharges occurred [27]. We explore the implications of this finding on the present and future burden of EP-associated GI illness in our quantitative burden of disease estimate.

Flooding, which can occur during EP, may also be associated with waterborne illness. Following severe flooding in the Midwest in 2001, the EPA [58] investigated the risk of GI illness among participants of a pre-existing drinking water intervention study. The incidence rate ratio for GI symptoms during the flood vs. prior to the flood was 1.29 (95\% CI: 1.06-1.58), with an increased effect among individuals with increased sensitivity to GI illness. GI symptoms were also associated with floodwater contact, particularly in children. In a case-crossover study of 129 floods in Massachusetts from 2003 to 2007, Wade et al. [59] observed an odds ratio of 1.08 (95\% CI: 1.03-1.12) for ED visits for GI illness in the $0-4$ day period after flooding.

People may be exposed to pathogens in contaminated surface water by ingestion, inhalation or dermal contact. These exposures may be due to 1 ) inadequate treatment at the water treatment plant, 2) contamination of drinking water in the treated water delivery system or 3) direct contact with contaminated surface water. Flooding, in particular, may contribute to human exposure of contaminated surface water via pathways (2) and (3) [60]. These indirect pathways between EP and illness are likely mediated by the quality of the drinking water treatment and delivery infrastructure as well as the sensitivity of the population to the microbes or their toxins.

\section{Multi-GCM ensemble projections \\ $E H$}

By ZIP code, average annual EH days ranged widely, from 0 to 16 days historically and $0-46$ days in the projected period (Table 2). By both ZIP code and county, the median projected average annual count of $\mathrm{EH}$ days was approximately 5 times higher than the historical count. The historical and projected counts of EH days were highly correlated (Spearman $r=0.99$ ), and the six counties (St. Joseph, Wayne, Berrien, Cass, Kalamazoo, and Monroe Counties) with the highest number of $\mathrm{EH}$ days were the same in both the historical and projected periods (Additional file 1: Appendix 5).

EP

In the historical period (1970-2000), there were, by definition, 7.3 EP days per year ( $2 \%$ of 365.25 ), so given an increase of 0.5-2.0 days per year statewide, EP days will increase to $7.8-9.3$ days per year. 
Table 2 Minimum, median and maximum average annual number of extreme heat days, or days where the maximum temperature was $32.2-34.9^{\circ} \mathrm{C}$ or $\geq 35^{\circ} \mathrm{C}$, in the historical (1971-2000) and projected (2041-2070) periods across ZIP codes and counties

\begin{tabular}{|c|c|c|c|c|c|c|}
\hline & \multicolumn{3}{|l|}{ Historical } & \multicolumn{3}{|l|}{ Projected } \\
\hline & Minimum & Median & Maximum & Minimum & Median & Maximum \\
\hline \multicolumn{7}{|l|}{ ZIP code } \\
\hline $32.2-34.9^{\circ} \mathrm{C}$ & 0.0 & 5.2 & 12.4 & 0.0 & 19.0 & 27.4 \\
\hline$\geq 35^{\circ} \mathrm{C}$ & 0.0 & 0.7 & 3.1 & 0.0 & 7.8 & 18.8 \\
\hline Total & 0 & 5.9 & 15.5 & 0.0 & 26.6 & 46.2 \\
\hline \multicolumn{7}{|l|}{ County } \\
\hline $32.2-34.9^{\circ} \mathrm{C}$ & 0.5 & 3.7 & 9.5 & 5.9 & 15.0 & 24.8 \\
\hline$\geq 35^{\circ} \mathrm{C}$ & 0.0 & 0.6 & 2.0 & 1.5 & 6.8 & 14.1 \\
\hline Total & 0.5 & 4.2 & 11.5 & 7.6 & 21.8 & 38.9 \\
\hline
\end{tabular}

\section{Historical disease burden of the health outcomes}

EH

The population age distribution changed from the historical to the projected period, with the percentage of older adults increasing from $12 \%$ to $18 \%$ statewide.

Across 83 counties, the daily baseline mortality rate for non-accidental deaths ranged from 1.8 to 5.3 deaths per 100,000 persons, with a median of 3.2 deaths per 100,000 persons in the historical period (Table 3 ). The median mortality rate in the projected period was slightly higher (3.3 deaths per 100,000 persons). We did not age-standardize these mortality rates, so the wide range of mortality rates partially reflects differing age distributions between counties. For renal hospitalizations, we estimated a statewide daily rate among non-whites in the warm season of 0.24 hospitalizations per 100,000 persons for both periods among individuals under 65 years of age. For older individuals, daily ED visits for non-accidental causes ranged from 34 to 56 visits per 100,000 persons in the historical period, and because of an increased percentage of older adults over time, the median in the projected period was again higher than in the historical period (53 vs. 44 visits per 100,000 persons).
EP

For both periods, we estimated a daily ED visit rate for gastrointestinal illness in Michigan of 3 visits per 100,000 residents. Because our exposure-response association is only applicable to communities where drinking water may be exposed to CSOs, this result applies only to the 5.8 million Michigan residents served by a community public water system receiving drinking water from the Great Lakes or connecting channels or from inland rivers and lakes [53].

\section{Exposure-outcome associations EH-mortality association}

We did not see a significant association between either EH threshold $\left(32.2-34.9, \geq 35^{\circ} \mathrm{C}\right)$ and mortality in the 0-4 or 5-19 age groups (Additional file 1: Appendix 4, Table A2). Among men ages 20-54, we found a risk of mortality $1.12(1.01-1.25)$ times that of women during $\geq 35^{\circ} \mathrm{C} \mathrm{EH}$ days, and we found an added risk of mortality among individuals without a high school degree in this age group, as well. Among individuals 55-64, we found a $1.07(1.00-1.14)$ risk of mortality during $\geq 35^{\circ} \mathrm{C}$ $\mathrm{EH}$ vs. non-EH (Additional file 1: Appendix 4, Table A2), but we did not find significant effect modification by any of the individual or area-level characteristics

Table 3 Minimum, median and maximum daily rate of deaths, hospitalizations, and emergency department (ED) visits across 83 Michigan counties in the historical (1971-2000) and projected (2041-2070) periods in the warm season

\begin{tabular}{|c|c|c|c|c|c|c|}
\hline & \multicolumn{3}{|l|}{ Historical } & \multicolumn{3}{|l|}{ Projected } \\
\hline & Minimum & Median $^{a}$ & $\overline{\operatorname{Max}}$ & Minimum & Median $^{a}$ & $\overline{\text { Maximum }}$ \\
\hline Non-accidental deaths & 1.8 & 3.2 & 5.3 & 2.0 & 3.3 & 4.8 \\
\hline Renal disease hospitalizations, non-whites, $<65$ years old & & 0.57 & & & 0.57 & \\
\hline Renal, heat and respiratory hospitalizations, ages 65 and older & 1.2 & 1.4 & 1.8 & 0.86 & 1.7 & 2.0 \\
\hline Non-accidental ED visits & 34 & 44 & 56 & 44 & 53 & 65 \\
\hline Gastrointestinal illness ED visits & & 3.0 & & & 3.0 & \\
\hline
\end{tabular}


tested. Among individuals ages 65 and older, we found similar risks within 10-year age groups, so these were combined as in Gronlund et al. [9]. In this age group, we found added risks among non-married individuals, and increased risk with increasing non-green space and increasing poverty at the ZIP-code level. We did not vary our AFs by marital status given that this characteristic varied little by ZIP code. Furthermore, we did not vary our AFs by non-green space given that similar land cover characteristics are used in deriving the historical and projected area-specific EH days. The increased vulnerability among residents of ZIP codes with high poverty rates was a different finding from Gronlund et al. [9], perhaps because our EH definition was more extreme than that used in Gronlund et al. [9].

For the 65 and older age group, we estimated an AF that was significantly greater than zero in $90 \%$ of the ZIP codes for $\mathrm{EH} \geq 35^{\circ} \mathrm{C}$. Of these, the estimated AFs ranged from 0.12 to 0.69 (results not shown). Of the ZIP codes with AFs of at least $0.30,36 \%$ were in Wayne County, MI. For $\mathrm{EH} \geq 35^{\circ} \mathrm{C}$ for men $20-49$, the AF for all ZCTAs was estimated as 0.091. Likewise, for individuals ages 55-64, the statewide AF was estimated as 0.066 .

\section{EH-hospitalization association}

Based on a statewide, all-ages RR of 1.31 for the risk of renal hospitalizations during $\mathrm{EH}$ days $\geq 32.2^{\circ} \mathrm{C}$ vs. non-EH days among non-whites, we estimated an AF of 0.24 among non-whites less than 65 years of age. Among individuals 65 years and older, we estimated ZIP-code-specific AFs EH days $\geq 32.2{ }^{\circ} \mathrm{C}$ ranging as high as 0.63 , among blacks 78 and older. Thirty-one percent of the 52 ZIP codes with AFs greater than 0.3 in any age-race group were in Wayne County, MI.

\section{$E H-E D$ visit association}

Based on the RRs presented in Kingsley et al. for non-accidental ED visits, we estimated AFs for EH days $32.2-34.9^{\circ} \mathrm{C}$ of 0.042 and 0.071 for the $0-18$ and 65 and older age groups, respectively. For $\mathrm{EH}$ days $\geq 35^{\circ} \mathrm{C}$, we estimated slightly higher AFs of 0.052 and 0.088 for the two respective age groups. For heat-related visits in the 18-64 age group, the AFs were much higher: 0.61 and 0.69 for $\mathrm{EH}$ days $32.2-34.9^{\circ} \mathrm{C}$ and $\mathrm{EH}$ days $\geq 35^{\circ} \mathrm{C}$, respectively.

\section{EP-ED visit association}

Based on an RR of 1.13 for the risk of an ED visit for a GI illness at the 99th percentile of EP, we estimated an $\mathrm{AF}$ of 0.12 for the residents receiving drinking water from a surface water source.

\section{EH- and EP-attributable health burdens \\ $E H$}

We estimated the rate of all non-accidental mortality associated with $\mathrm{EH}$ days to increase sixfold from 0.46 per 100,000 adults aged 20 years and older in the historical period (33 deaths annually statewide, Table 4) to 2.9 per 100,000 adults (240 deaths annually statewide, Table 4) in the projected period. There was significant heterogeneity between counties, with a 19 -fold variation in mortality rate between counties in the historical period and a nine-fold variation between counties in the projected period (Fig. 2a-b, Additional file 1: Appendix 5).

Mortality was highest among older adults, and the proportion of $\mathrm{EH}$ associated deaths that occurred in the 65 and older age group increased from the historical to the projected period ( $87 \%$ and $91 \%$, respectively, Fig. 3), due to the increased percentage of the population of individuals 65 and older.

$\mathrm{EH}$-associated hospitalization rates also ranged widely by county, ranging from 0.002 to 0.58 per 100,000 persons in the historical period, and 0.03 to 2.5 per 100,000 persons in the projected period. We estimated the annual statewide number of $\mathrm{EH}$-attributable hospitalizations to increase from 28 in the baseline period to 185 in the projected period (Table 4).

EH-associated ED visit rates were substantially higher than $\mathrm{EH}$-associated hospitalization rates, with rates of 12 per 100,000 persons (1218 visits statewide) in the historical period and 68 per 100,000 persons (7845 visits statewide) in the projected period (Table 4). Given that ED visit rates were much higher than hospitalization rates for EH, we focused the subsequent analyses and discussion of $\mathrm{EH}$-associated morbidity on $\mathrm{EH}$-associated ED visits. Significant heterogeneity between counties was seen, with a 16-fold variation in ED rate between counties at historical and a 6-fold variation in ED rate between counties in the projected period (Fig. 2c-d, Additional file 1: Appendix 5).

\section{EP}

Multiplying our estimates of the AF, EP days, GI-illness ED visit incidence rate, and population, we estimated a historical burden-of-disease rate of ED visits for GI illness attributable to EP as $170 \mathrm{ED}$ visits annually, or a rate of 1.7 visits per 100,000 Michigan residents. Assuming an increase of approximately 1 day of EP in the future period, we estimated a future burden of waterborne disease attributable to EP as $220 \mathrm{ED}$ visits annually, or 1.9 visits per 100,000 Michigan residents (Table 4). Considering that the number of days by which EP events will increase is projected to range spatially between 0.5 days to 2.0 days, depending on the region in Michigan, the EP-associated ED visit rate increase may range spatially from 1.0 to 3.82 visits per 100,000 Michigan residents. 
Table 4 Central estimates of historical (1971-2000) and projected (2040-2070) annual counts and rates (per 100,000 persons) of disease burden and estimated cost attributable to extreme heat (EH) or extreme precipitation (EP) for the State of Michigan

\begin{tabular}{lllllll}
\hline Outcome & Historical Count & Historical Rate & Historical Cost & Projected Count & Projected Rate $^{\text {Projected Cost }^{\mathrm{a}}}$ \\
\hline EH mortality & 33 & 0.46 & $\$ 42$ million & 240 & 2.9 & \$280 million \\
EH hospitalizations & 28 & 0.28 & $\$ 240,000$ & 185 & 1.6 & $\$ 1.6$ million \\
EH ED visits & 1200 & 12 & $\$ 2.2$ million & 7800 & 68 & $\$ 14$ million \\
EP GI illness ED visits & 170 & 1.7 & $\$ 370,000$ & 220 & 1.9 & $\$ 480,000$
\end{tabular}

${ }^{a}$ Assuming, per person: $\$ 129,000$ per life-year [29] and age-specific life expectancies for persons who eventually died of circulatory or respiratory disease [34]; Michigan 2014 renal hospitalization costs of $\$ 9000$ [21]; Michigan 2014 respiratory hospitalization costs of $\$ 8400$ [21]; heat-related hospitalization cost of $\$ 5400$ with additional costs of $\$ 1500$ among ages $65-77$ and $\$ 1600$ among ages 78 and older $\{$ Schmeltz, $2016 \# 2143 ;\{$ Kingsley, $2015 \# 1867\}$; non-accidental ED visit cost of $\$ 1800$ and gastrointestinal infection ED visit cost of $\$ 2200$, based on 2015 median costs [31]

\section{Monetary costs}

The cost of EH-associated mortality across the State of Michigan was $\$ 280$ million in the projected period and $\$ 42$ million in the historical period, based on a value per life-year of $\$ 129,000$. The projected cost of EH-associated morbidity was dominated by EH-associated ED visits, estimated at \$14 million, or \$12 million higher than the historical cost (Table 4). EP costs were similar in the historical and projected periods: $\$ 390,000$ and $\$ 480,000$, respectively.

\section{Uncertainties}

Table 5 summarizes the uncertainties in estimating the burden of disease due to climate.

\section{Baseline health effect estimates}

For the historical estimates, our uncertainty in the baseline mortality estimates is low given that over $99 \%$ of deaths in the U.S. are thought to be registered [61]. Despite not having county-specific historical hospitalization data for our study, our estimate of uncertainty in hospitalization rates by race and age is also low, given that over $50 \%$ of the state's black population lives in the counties for which we had detailed warm-season hospitalization rates by race and cause. Furthermore, the all-cause renal hospitalization rate in the 3 counties of $12.2 \%$ in 2014 is very close to the statewide rate of $12.5 \%$ [62]. We did not have county-specific or even statewide ED visit rates available for this study. In comparing
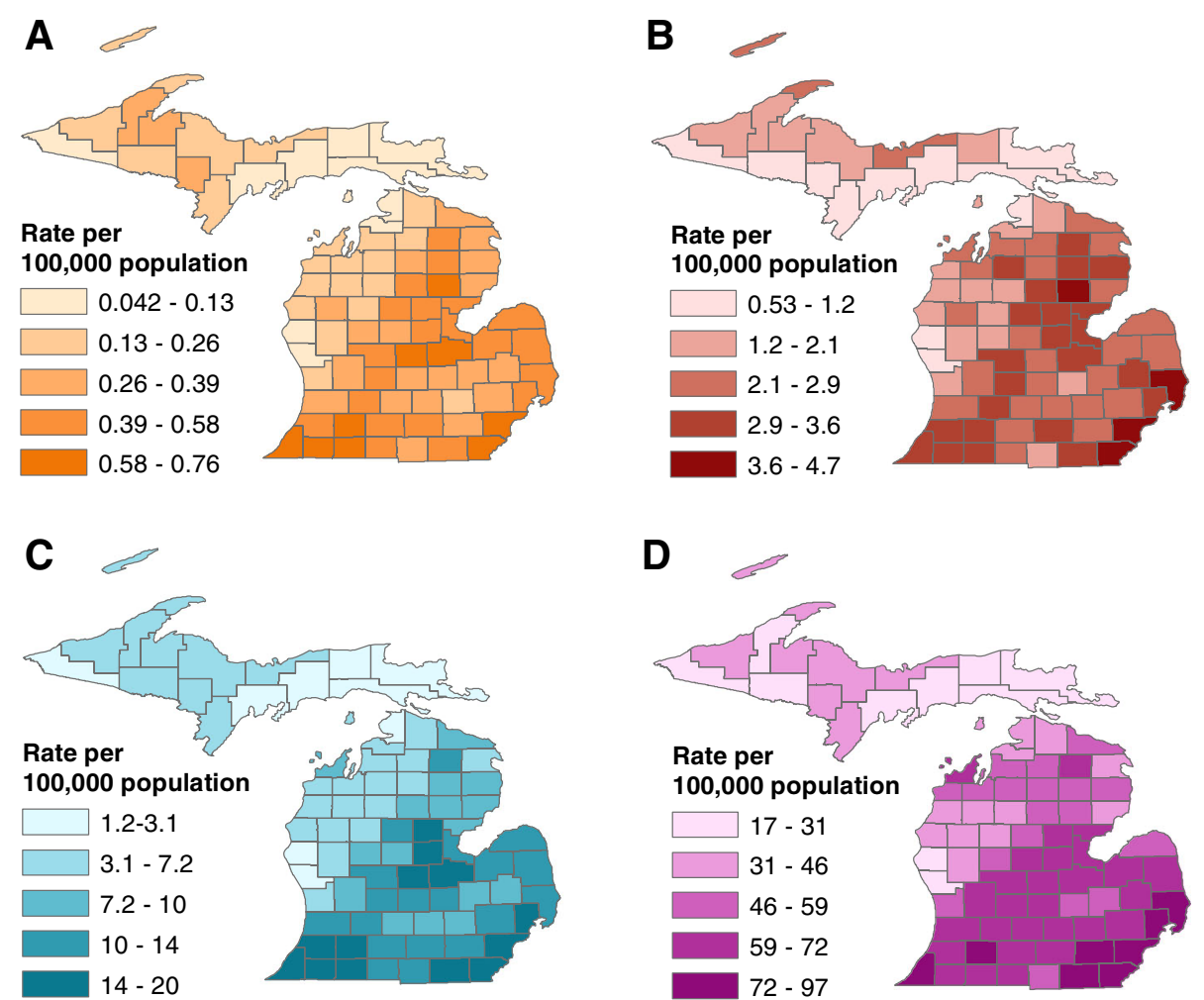

Fig. 2 Annual heat-attributable mortality rate 1971-2000 (a) and 2041-2070 (b) and heat-attributable emergency department (ED) visit rate 1971-2000 (c) and 2041-2070 (d) by county 

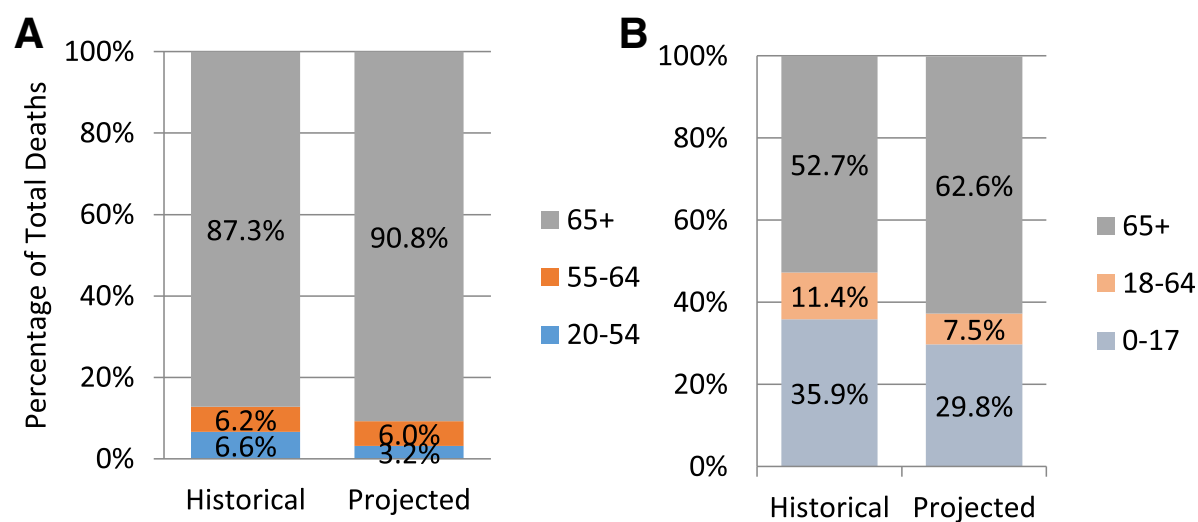

Fig. 3 Percentage of heat-attributable deaths (a) and heat-attributable emergency department visit rates (b), by age group and time period

statewide rates among the Midwest states for which data were available, we found a maximum absolute percent difference around the Midwest estimate for the heat-related ED visits of 57\%, giving us moderate uncertainty in our baseline ED-visit-rate estimates (Additional file 1: Appendix 3).

Uncertainties in the projected baseline health effect estimates were moderate, based on recent trends. Age-adjusted renal hospitalization rates increased 30\% over 12 years, from 100 per 100,000 persons in 20012003 to 130 per 100,000 persons 2012-2014. Trends in ED visit rates from 2006 to 2011 varied depending on diagnosis, with the steepest increase of $74 \%$ for septicemia [35]; but overall, ED visit rates increased $4.5 \%$ in this 6-year time period.

\section{Population projections}

Estimated mortality and morbidity impacts varied by population projection. The statewide EH-associated mortality rate estimated using the 2050 ICLUS A2 population estimates was $3 \%$ below that using the Woods \&
Poole central-case scenario while the EH-associated ED visit and hospitalization rates were $50 \%$ and $44 \%$ higher, respectively, than those using the Woods \& Poole scenario. This suggests our estimates of future EH-attributable mortality are only mildly sensitive to assumptions about population growth and migration, but our morbidity estimates are moderately sensitive to population change assumptions.

\section{Exposure estimates}

A large source of uncertainty is that in the climate projections. The bias in number of days with maximum temperature $>32.2{ }^{\circ} \mathrm{C}$ for the A2 scenario from the six GCMs that were used to generate the Michigan-specific projections range ranged from $-50 \%$ to $+20 \%$ in Michigan. For EP, bias in wet days with $>3$ in. of precipitation, the A2 scenario-specific biases range from - 90\% to $100 \%$ in Michigan, depending on the GCM and the region [15]. Therefore, projections of increases could reasonably range from almost no increase in EP days to twice as many days as projected by the ensemble climate

Table 5 Characterization of uncertainty* by source in the estimates of the annual burden of disease attributable to extreme heat (EH) and extreme precipitation (EP) exposures in the historical (1971-2000) and projected (2040-2070) periods

\begin{tabular}{|c|c|c|c|c|c|}
\hline Exposure and Response & Baseline health effect estimate & Population estimate & Exposure estimate & Exposure-response association & Costs \\
\hline \multicolumn{6}{|l|}{ Historical } \\
\hline EH-mortality & Low & Low & Low & Moderate & High \\
\hline EH hospitalizations & Low & Low & Low & Moderate & Moderate \\
\hline EH-ED visits & Moderate & Low & Low & Moderate & Moderate \\
\hline EP-GI illness ED visits & Moderate & Low & Low & Moderate & Moderate \\
\hline \multicolumn{6}{|l|}{ Projected } \\
\hline EH-mortality & Moderate & Moderate & Moderate & Moderate & High \\
\hline EH-renal hospitalizations & Moderate & Moderate & Moderate & Moderate & High \\
\hline EH-ED visits & Moderate & Moderate & Moderate & Moderate & High \\
\hline EP-GI illness ED visits & Moderate & Moderate & High & High & High \\
\hline
\end{tabular}

*Approximate range of the uncertainty around the central estimate: Low $= \pm 49 \%$, Moderate $=-99 \%$ to $-50 \%$ or $+50 \%$ to $+99 \%$, High $=\leq-100 \%$ or $\geq+200 \%$ 
projection. Global and downscaled climate projections may contain additional biases not quantified above, especially near the Great Lakes region. The spatial resolution of GCMs does not allow for accurate representation of the lakes' influence on local and regional climate; at best, GCMs may capture the large-scale regional effects of the lakes [63]. Furthermore, assigning EH and EP projections to ZIP codes, which are smaller than 1/8-degree, adds an additional source of uncertainty. With regards to historical EP exposure estimates, those used in deriving the precipitation exposure-response association were from single monitors rather than modeled data with high spatial resolution. Given the spatially heterogeneous nature of precipitation, this may result in bias of the effect estimates towards the null, as was demonstrated in a recent simulation study of precipitation health effects [64].

\section{Exposure-response associations}

Another large source of uncertainty is in our estimate of the RRs. For the EH-hospitalization estimate among individuals under 65 years of age, the $95 \%$ confidence intervals ranged from $\pm 80 \%$ around the point estimate. Among individuals 65 and older, the 95\% confidence interval for the median $R R$ estimate (1.13) of hospitalization ranged from $\pm 40 \%$ around the point estimate. For the EH-mortality estimates, for which we had a large Michigan-specific data set, the $95 \%$ confidence intervals around the RRs corresponded to increases of more than $100 \%$ or decreases of close to $100 \%$ in the AFs. For the EH-ED associations, the 95\% confidence intervals ranged as high as $52 \%$ above the point estimate. Additionally, the cumulative effects in the days following the exposure, i.e., the lagged effects, were not estimated in the EH-ED source study, further contributing to uncertainty in the net effect of EH on ED visits.

Several recent studies have found a substantial decrease in the association between $\mathrm{EH}$ and mortality over time [65], suggesting strong technological and/or behavioral adaptation to $\mathrm{EH}$. Nordio et al. found a decrease in the RR for mortality at $27^{\circ} \mathrm{C}$ vs. $16^{\circ} \mathrm{C}$ for the climate region containing Michigan, from 1.25 in the 1962-1966 time period to 1.08 in the 2000-2006 time period [66]. Likewise, Bobb et al. found that excess deaths per 1000 deaths attributable to each $5.6^{\circ} \mathrm{C}$ increase in summer temperature declined from 50 per 1000 in 1987 to 11 per 1000 in 2005 in the Industrial Midwest [67]. In New York City, in a climate similar to that of Michigan's, Petkova et al. found a decline in RR for mortality at $29^{\circ} \mathrm{C}$ vs. $22^{\circ} \mathrm{C}$ over 11 decades, from 1.43 in the 1900 s to 1.09 in the 2000s [68]. Although all of these studies show a leveling off of this decline in recent years, changes in the RRs or attributable deaths over time of $60-80 \%$ for the mortality outcomes suggest that change over time for all of the exposure-response associations remains a source of moderate uncertainty.

External validity is another source of uncertainty in our EH-ED and EP-ED exposure-response estimates. For these estimates, we chose studies from similar climates, but population and infrastructure differences may affect the portability of RRs between two states. Michigan differs from Rhode Island in its demographic structure, with, for example, $14 \%$ vs. $8 \%$ of the population identifying as black [69]. With regards to the EP exposure-response estimate, Michigan likely differs from Massachusetts in its water delivery infrastructure, its demographic structure, and the sensitivity of its population to waterborne pathogens.

For EP, several studies of the association between precipitation and gastrointestinal illness did not find evidence of an association [28]. Jagai et al. may have been able to detect this association because they stratified their analysis by CSO exposure [27]. Additionally, in estimating the burden of disease, we applied RRs derived from a study defining EP at the 99th percentile of daily precipitation to exposure estimates of EP defined at the 98th percentile of daily precipitation, which might slightly overestimate the burden.

Communities across the State of Michigan are in the process of eliminating CSOs. However, a recent study in Massachusetts [70] found associations between sanitary sewer overflows (SSOs) and GI ED visits, suggesting that separating the sanitary and storm sewers will not entirely eliminate the pathway by which sewage can affect GI ED visits during future EP events.

\section{Monetary costs}

Our uncertainty in the costs associated with the historical and projected outcomes was moderate to high. For the costs associated with $\mathrm{EH}$-attributable mortality, we were limited in our lack of estimates of years-of-life-lost. The time series and case-crossover study designs, on which our estimates were based, cannot estimate by how many months or years the deaths were advanced. Our approach of using the reduced life expectancies among individuals who die of cardiovascular or respiratory diseases attempts to account for this, but uncertainty in the degree of mortality displacement remains high. Uncertainty in the cost of a life-year is also high, with a reported range of $\$ 65,000$ to $\$ 490,000$ [29]. For the morbidities, uncertainties in the estimated costs were moderate. The reported ranges were less than $\pm 50 \%$ around the point estimates for hospitalization costs [30], but we are uncertain as to how well the estimates reflected the cost of an EH-associated visit that was not necessarily coded as heat-related. Specifically, we used heat-related hospitalization costs to estimate $\mathrm{EH}$-associated renal and respiratory hospitalizations, and we used non-accidental ED visit costs to estimate ED visits that were presumably triggered by $\mathrm{EH}$. 
We have additional uncertainty in projecting the costs given trends in medical costs over time. For example, in 2011 dollars, the average cost of an ED visit for individuals age 65 and older increased $40 \%$ over just 10 years from $\$ 630$ in 2001 to $\$ 880$ in 2011 [71]. Similarly, daily inpatient costs increased 30\% from $\$ 2400$ to $\$ 3200$.

\section{Discussion}

The health burden due to $\mathrm{EH}$ and EP may significantly rise for all Michigan counties by midcentury, with the greatest mortality and ED-burden in the southeast. To provide a sense of the public health significance of our projections, the projected combined EH- and EP-attributable ED burden in Southeast Michigan, as high as $0.97 / 1000$ persons, is not as high as the 2012-2013 national motor-vehicle accident ED visit rate of 10/1000 persons [72], but it is comparable to the 2014 national ED-visit rate for miscarriages of 1.2/1000 persons [73]. Adaptation measures against extreme temperatures are needed to protect health, such as targeted public health monitoring, expanded access to air conditioning, and reductions in the urban heat island effect. Health protection of older adults should be prioritized in public health planning given the large burden among those aged 65 and older.

These estimates represent the total non-accidental effects of $\mathrm{EH}$ as identified in the Michigan-specific causal pathway, including effects which may be mediated by ozone. It is not likely that ozone strongly mediates the $\mathrm{EH}$-mortality or EH-hospitalization effects given that its inclusion in models of the association between $\mathrm{EH}$ and mortality and hospitalizations in Michigan did not affect the estimates of the $\mathrm{EH}$ effects by more than 10\% [9, $18]$. We did not have projected increases in ozone concentrations and could not estimate its projected direct effect, independent of EH. However, a projection of mortality in 2041-2050 due to ozone in 19 communities in the Southeastern U.S. found a small, $0.43 \mathrm{ppb}$ increase in average ozone concentration due to climate change as compared to concentrations in 2000 and a concomitant $0.01 \%$ increase in the mortality rate attributable to climate-change related increases in ozone [74]. A study of the New York City metropolitan region projected a $7.3 \%$ increase in ozone-related asthma emergency department visits among children by the 2020 s as compared to 1990s [75], suggesting modest independent effects of ozone.

In addition to potential increases in ozone, some of the historical and projected ED visits which we attributed to EH may be among individuals experiencing asthma exacerbations. Several studies have found associations between temperature and asthma symptoms or $\mathrm{ED}$ visits. Winquist et al. found a $6 \%$ increase in the risk of ED visits for asthma among children in Atlanta at the 75 th vs. 25 th percentile of daily maximum temperature
[76]. In Australia, Li et al. found increased reports of wheeze/chest tightness and cough/phlegm with increasing temperatures in a cohort of 270 children with asthma [77], and pediatric ED visits for chronic lower respiratory diseases increased in association with high temperatures in a separate study in Brisbane, Australia [78]. Hospitalizations were increased for asthma and other respiratory conditions in New York City [79]. An evaluation of pediatric records from a Detroit hospital found an additional 1.8 asthma ED visits for a $10^{\circ} \mathrm{F}$ increase in temperature [80]. We did not quantify the specific morbidity burden of asthma attributable to $\mathrm{EH}$, but given the high prevalence of asthma in the State of Michigan [81], EH-associated asthma morbidity may be of particular concern in Michigan with climate change.

Although reviews on preterm birth and heat published prior to this project's scoping phase suggested that the association was unclear [82, 83], several studies have been published more recently indicating an association between birth outcomes and heat [84-94]. Future burden of disease assessments in Michigan should consider birth outcomes, particularly in light of the high baseline preterm birth rate in Detroit [95]. Similarly, we did not identify injuries, including occupational injury not listed as heat-related, or self-inflicted injuries as EH-associated concerns in the scoping phase. Recent research indicates significant associations of non-heat-related injuries with EH $[96,97]$, and future Michigan climate burden of disease assessments should consider $\mathrm{EH}$-associated injuries.

Climate change may have significant impacts on public health beyond EH and EP impacts beyond those quantified in this paper. Notably, pollen levels are expected to increase in North America [98]. Temperature and precipitation, as well as carbon dioxide concentrations, affect the levels of several types of tree and grass pollen, and this may lead to increases in allergic respiratory morbidity [99]. Furthermore, the pollen season length is increasing with climate change, although research on pollen trends is lacking due to a lack of consistent pollen monitoring over a long timescale [98]. Future research should address the impacts of higher pollen levels on asthma and allergy incidence and exacerbation.

We have only calculated the EP-attributable burden of GI illness related to ED visits. Most people experiencing GI illness do not seek treatment in EDs or medical care of any kind. Using a variety of surveillance systems, Mead et al. estimated that the average person experiences 1.05 episodes of GI illness annually characterized by diarrhea, vomiting or both [100]. By this estimate, GI-related ED visits underestimate the total burden of GI-related illness by a factor of 100, and our estimate of the burden of GI illness attributable to EP is severely underestimated by our EP-attributable burden of GI-related ED visits. Furthermore, our quantitative EP 
estimate may not have accounted for the effects of harmful algal blooms, which may affect Michigan and Massachusetts drinking water delivery systems differently.

We did not project increases in legionellosis with EP given the inconsistency in the literature in associations between legionellosis and precipitation. However, some of the studies suggested a greater importance of temperature and humidity than EP in legionellosis incidence, and confidence that temperature will increase with climate change is high.

Several limitations to our estimates of the burden of future EH and EP exist, largely stemming from uncertainty surrounding various model inputs. The uncertainty analysis indicated that our mortality projections are only mildly sensitive to different population assumptions. Other inputs, including the exposure data and exposure-response function, carry greater uncertainty. A key limitation in our approach is the use of historical relationships for the estimation of future health effects without accounting for long-term adaptation to $\mathrm{EH}$ or EP. Physiological and behavioral adaptations have the potential to reduce the impact of extreme weather. Our results may therefore be regarded as a direr scenario where effective public health measures protecting individuals from extreme weather events have not been adopted.

Additionally, our analysis does not fully account for uncertainty in climate models or future climate conditions. Our projections of $\mathrm{EH}$ days were derived using the high emissions A2 scenario, although the lower emissions scenarios are becoming statistically improbable given recent historic emissions trends [101]. Incorporating exposure projections derived from alternate, low emissions scenarios would likely result in lower mortality estimates. On the other hand, evidence from other studies suggests that mortality and morbidity increase at less extreme temperatures in temperate climates such as Michigan [8, 25]. This would imply that our results underestimate the total number of deaths and ED visits associated with this climate scenario.

\section{Conclusions}

Under a dire climate change scenario, we estimated a Michigan-wide increase in EH-associated mortality from $0.46 / 100,000$ persons historically to $2.9 / 100,000$ in the projected period for $\$ 280$ million in costs. We estimated a more substantial increase in EH-associated ED visits from $12 / 100,000$ persons to $68 / 100,000$ persons, for 7800 $\mathrm{EH}$-attributable emergency department visits and \$14 million in costs. EP-associated ED visits increased minimally from 1.7 to $1.9 / 100,000$ persons, although this quantitative estimate did not include self-treated gastroenteritis or sufficiently represent the range of health problems from harmful algal blooms, flooding, and legionellosis. With the use of a high-emissions climate scenario and the exclusion of adaptation in the model we may over-estimate the future burden due to extreme temperatures in Michigan, but the exclusion of health effects from moderate heat, pollen, and precipitation-associated respiratory effects as well as any non-emergent health effects may result in substantial underestimation of both the present and future burden of climate in Michigan. Further research should investigate the association between moderate heat, precipitation, pollen, and health to gain a more complete picture of Michigan's climate-related disease burden. Our finding of a notable burden of mortality and morbidity attributable to $\mathrm{EH}$, without assumptions about adaptation, stresses the importance of actions to protect health against the adverse health effects of EH. Additionally, although the uncertainty in the GI-illness projections is high, the health risks of poor public drinking water quality that can result from harmful algal blooms and storm-related emergencies are clear. In these emergencies, access to clean water for drinking and bathing can become challenges, and preparations for increases in EP events should focus on distribution of clean, potable water in emergencies to affected residents to avoid waterborne illnesses.

\section{Additional file}

Additional file 1: Appendix 1. Additional details on methods [104]. Appendix 2. Deriving ZCTA-level estimates for EH days. Appendix 3. Derivation of ED visit rates. Appendix 4. Heat-mortality epidemiologic results. Appendix 5. County-specific inputs and results [105]. Appendix 6. Loading data into BenMAP. (DOCX $75 \mathrm{~kb}$ )

\section{Abbreviations}

AF: Attributable fraction; AFD: Attributable fraction day; BenMAP: Environmental Benefits Mapping and Analysis Program; BOD: Burden of disease; ED: Emergency department; EH: Extreme heat: EP: Extreme precipitation; EPA: U.S. Environmental Protection Agency; GCM: Global climate model; Gl: Gastrointestinal; HAB: Harmful algal bloom; HCUP: Healthcare Cost and Utilization Project; ICD: International Classification of Diseases; ICLUS: Integrated Climate and Land-Use Scenarios;

QALY: Quality-adjusted life year; RR: Risk ratio; ZCTA: ZIP code tabulation area

\section{Acknowledgements}

We thank Daniel Brown and William "B.J." Baule of the Great Lakes Integrated Sciences + Assessments Center, Richard Pollman of the National Weather Service, Neal Fann of the Environmental Protection Agency, and Lily Tyndall Snow of the Michigan Department of Health and Human Services for their generous and prompt sharing of data and insights.

\section{Funding}

This work was supported by a Michigan Institute for Clinical and Health Research Postdoctoral Translational Scholars Fellowship (2UL1TR000433-06), National Institutes of Health grants K99ES026198 and P30 ES017885; National Institute for Occupational Safety and Health grant T42 OH008455-09, and Cooperative Agreement Number EH001124 from The Centers for Disease Control and Prevention (CDC). Its contents are solely the responsibility of the authors and do not necessarily represent the official views of the CDC or the Michigan Department of Health and Human Services.

\section{Availability of data and materials}

The mortality and hospitalization records used during the current study are not publicly available to protect the confidentiality of the subjects. These 
records may be requested for research purposes from the Michigan Department of Health and Human Services. The weather data used in epidemiologic analyses in the current study are available from the National Climatic Data Center [102]. The ED visit data were derived from Healthcare Cost and Utilization Project data [21]. The climate data, historical and projected, are available from the Great Lakes Integrated Sciences + Assessments Center on request (glisa.msu.edu).

\section{Authors' contributions}

CJG participated in acquiring the data, performing, interpreting, and revising the analyses and drafting and revising the manuscript. LC participated in acquiring the primary funding and data, analyzing and interpreting the data, and revising the manuscript. CS participated in acquiring the data, performing and interpreting the analyses, and drafting the manuscript. MSO participated in acquiring the data, interpreting the data and revising the manuscript. All authors read and approved the final manuscript.

\section{Ethics approval and consent to participate}

The Institutional Review Boards of the Michigan Department of Health and Human Services and the University of Michigan have deemed this study "not regulated."

\section{Consent for publication}

NA

\section{Competing interests}

The authors declare that they have no competing interests.

\section{Publisher's Note}

Springer Nature remains neutral with regard to jurisdictional claims in published maps and institutional affiliations.

\section{Author details}

${ }^{1}$ Center for Social Epidemiology and Population Health, University of Michigan School of Public Health, 1415 Washington Heights, Ann Arbor, Ml 48109-2029, USA. ${ }^{2}$ Michigan Climate and Health Adaptation Program, Division of Environmental Health, Michigan Department of Health and Human Services, 333 S. Grand Ave, Lansing, MI 48909, USA. ${ }^{3}$ Departments of Epidemiology and Environmental Health Sciences, University of Michigan School of Public Health, 1415 Washington Heights, Ann Arbor, Ml 48109-2029, USA.

\section{Received: 21 April 2018 Accepted: 16 April 2019}

Published online: 27 April 2019

\section{References}

1. Cameron L, Stanbury M, Wahl R, Manente S: Michigan Climate and Health Adaptation Plan (MI-CHAP) 2010-2015 Strategic Plan. Edited by Michigan Department of Health and Human Services (MDHSS), Division of Environmental Health; 2011.

2. IPCC. Summary for policymakers. United Kingdom and New York; 2013.

3. Kunkel KE, Stevens LE, Sun L, Janssen E, Wuebbles D, ., Dobson JG: Regional Climate Trends and Scenarios for the U.S. National Climate Assessment: Part 3. Climate of the Midwest U.S. Edited by National Oceanic and Atmospheric Administration. Washington, D.C.; 2013.

4. Hess JJ, Saha S, Schramm PJ, Conlon KC, Ueijio CK, Luber G. Projecting climate-related disease burden: a guide for health departments. Atlanta: Edited by Centers for Disease Control and Prevention; 2014

5. Great Lakes Integrated Sciences and Assessments (GLISA). 2015. Great Lakes Regional Climate Change Maps. 2016. Available: http://glisa.umich.edu/ resources/great-lakes-regional-climate-change-maps. Accessed 2 Nov 2018.

6. Maurer EP, Wood AW, Adam JC, Lettenamier DP, Nijssen B. A long-term hydrologically-based data set of land surface fluxes and states for the coterminous United States. J Clim. 2002;15:3237-51.

7. National Weather Service, Detroit/Pontiac Office. 2018. Heat Awareness. Available: https://www.weather.gov/dtx/heataware2 [Accessed 2 Nov 2018].

8. Gasparrini A, Guo Y, Hashizume M, Lavigne E, Zanobetti A, Schwartz J, Tobias A, Tong S, Rocklov J, Forsberg B, et al. Mortality risk attributable to high and low ambient temperature: a multicountry observational study. Lancet. 2015;386(9991):369-75.
9. Gronlund CJ, Berrocal VJ, White-Newsome JL, Conlon KC, O'Neill MS Vulnerability to extreme heat by socio-demographic characteristics and area green space among the elderly in Michigan, 1990-2007. Environ Res. 2015; 136:449-61.

10. Armstrong B, Bell ML, de Sousa Zanotti Stagliorio Coelho M, Leon Guo Y-L, Guo Y, Goodman P, Hashizume M, Honda Y, Kim H, Lavigne E, et al. Longerterm impact of high and low temperature on mortality: an international study to clarify length of mortality displacement. Environ Health Perspect. 2017;125(10):-107009.

11. Saha MV, Davis RE, Hondula DM. Mortality displacement as a function of heat event strength in 7 US cities. Am J Epidemiol. 2013.

12. Saha MV, Davis RE, Hondula DM. Saha et al. respond to "mortality displacement after heat waves". Am J Epidemiol. 2014;179(12):1407-8.

13. Armstrong B, Gasparrini A, Hajat S. Estimating mortality displacement during and after heat waves. Am J Epidemiol. 2014;179(12):1405-6.

14. Walsh J, Wuebbles D, Hayhoe K, Kossin J, Kunkel K, Stephens G, Thorne P, Vose R, Wehner M, Willis J, et al. Ch. 2: Our Changing Climate. In: Melillo JM, Richmond TC, Yohe GW, editors. Climate Change Impacts in the United States: The Third National Climate Assessment: U.S. Global Change Research Program; 2014. p. 19-67.

15. Hayhoe K, Stoner A, Yang X, Crow C, Swaminathan R, Scott-Fleming I, Ryu J-H, Gelca R, Swain S. Development and dissemination of a highresolution National Climate Change Dataset: United States Geological Survey Report; 2013.

16. U.S. EPA. 2015. U.S. Environmental Protection Agency (EPA) environmental benefits mapping and analysis program-community edition (BenMAP-CE). Available: retrieved from: https://www.epa.gov/benmap 2016

17. RTI International: User's manual appendices. Environmental Benefits Mapping and Analysis Program - Community Edition. Edited by U.S. Environmental Protection Agency; 2015.

18. Ogbomo AS, Gronlund CJ, O'Neill MS, Konen T, Cameron L, Wahl R. Vulnerability to extreme-heat-associated hospitalization in three counties in Michigan, USA, 2000-2009. Int J Biometeorol. 2016:1-11.

19. Missouri Census Data Center. 2016. Standard Summary File 1 (2010 Census) Extract Assistant. Available: http://mcdc.missouri.edu [Accessed 4 Aug 2016].

20. Gronlund CJ, Zanobetti A, Wellenius GA, Schwartz JD, O'Neill MS. Vulnerability to renal, heat and respiratory hospitalizations during extreme heat among U.S. elderly. Clim Chang. 2016;136(3):631-45.

21. U.S. Department of Health and Human Services. HCUPnet: Healthcare Cost and Utilization Project Free Healthcare Statistics. 2016. Available: http:// hcupnet.ahrq.gov. Accessed 2 Nov 2018.

22. U.S. EPA. Land-use scenarios: National-Scale Housing-Density Scenarios Consistent with climate change storylines (final report). EPA/600/R-08/076F. 2009 Available: https://cfpub.epa.gov/ncea/global/recordisplay.cfm?deid=203458. Accessed 2 Nov 2018.

23. Gronlund CJ. Racial and socioeconomic disparities in heat-related health effects and their mechanisms: a review. Curr Epidemiol Rep. 2014;1(3):165-73.

24. Gronlund CJ, Zanobetti A, Schwartz JD, Wellenius GA, O'Neill MS. Heat, heat waves and hospital admissions among the elderly in the United States, 1992-2006. Environ Health Perspect. 2014;122(11):1187-92.

25. Kingsley SL, Eliot MN, Gold J, Vanderslice RR, Wellenius GA. Current and Projected Heat-Related Morbidity and Mortality in Rhode Island. Environ Health Perspect. 2015

26. Peel MC, Finlayson BL, McMahon TA. Updated world map of the KöppenGeiger climate classification. Hydrol Earth Syst Sci. 2007;11(5):1633-44.

27. Jagai JS, Li Q, Wang S, Messier KP, Wade TJ, Hilborn ED. Extreme Precipitation and Emergency Room Visits for Gastrointestinal IIIness in Areas with and without Combined Sewer Systems: An Analysis of Massachusetts Data, 2003-2007. Environ Health Perspect. 2015;123:9.

28. Guzman Herrador BR, de Blasio BF, MacDonald E, Nichols G, Sudre B, Vold L, Semenza JC, Nygard K. Analytical studies assessing the association between extreme precipitation or temperature and drinking water-related waterborne infections: a review. Environ Health. 2015;14:29.

29. Lee CP, Chertow GM, Zenios SA. An empiric estimate of the value of life: updating the renal Dialysis cost-effectiveness standard. Value Health. 2009;12(1):80-7.

30. Schmeltz MT, Petkova EP, Gamble JL. Economic Burden of Hospitalizations for Heat-Related IIInesses in the United States, 2001-2010. Int J Environ Res Public Health. 2016;13:9.

31. Agency for Healthcare Research and Quality. 2017. Medical Expenditure Panel Survey: Health Care Costs/Expenditures. Available: https://meps.ahrq gov/mepsweb/data_stats/download_data_files.jsp [Accessed 4 Aug 2017]. 
32. Voorhees AS, Fann N, Fulcher C, Dolwick P, Hubbell B, Bierwagen B, Morefield $\mathrm{P}$. Climate change-related temperature impacts on warm season heat mortality: a proof-of-concept methodology using BenMAP. Environ Sci Technol. 2011:45(4):1450-7.

33. U.S. Environmental Protection Agency. Land-Use Scenarios: National-Scale Housing Density Scenarios Consistent with Climate Change Storylines. Washington, D.C; 2009.

34. Centers for Disease Control and Prevention, National Center for Health Statistics. Underlying Cause of Death 1999-2015 on CDC WONDER Online Database. 2016

35. Skinner HTHA, Blanchard JR, Elixhauser AA. Trends in emergency department visits, 2006-2011. Rockville; 2014.

36. Basu R. High ambient temperature and mortality: a review of epidemiological studies from 2001 to 2008. Environ Health. 2009;8(1):40.

37. Gosling S, Lowe J, McGregor G, Pelling M, Malamud B. Associations between elevated atmospheric temperature and human mortality: a critical review of the literature. Clim Chang. 2009;92(3):299-341.

38. Li M, Gu S, Bi P, Yang J, Liu Q. Heat waves and morbidity: current knowledge and further direction-a comprehensive literature review. Int J Environ Res Public Health. 2015:12(5):5256-83.

39. Carlton EJ, Eisenberg JN, Goldstick J, Cevallos W, Trostle J, Levy K. Heavy rainfall events and diarrhea incidence: the role of social and environmenta factors. Am J Epidemiol. 2014;179(3):344-52.

40. Bush KF, Luber G, Kotha SR, Dhaliwal RS, Kapil V, Pascual M, Brown DG Frumkin H, Dhiman RC, Hess J, et al. Impacts of climate change on public health in India: future research directions. Environ Health Perspect. 2011; 119(6):765-70

41. Reynolds KA, Mena KD, Gerba CP. Risk of waterborne illness via drinking water in the United States. Rev Environ Contam Toxicol. 2008:192:117-58.

42. Cann KF, Thomas DR, Salmon RL, Wyn-Jones AP, Kay D. Extreme water-related weather events and waterborne disease. Epidemiol Infect. 2013;141(4):671-86.

43. Garcia-Vidal C, Labori M, Viasus D, Simonetti A, Garcia-Somoza D, Dorca J, Gudiol F, Carratala J. Rainfall is a risk factor for sporadic cases of Legionella pneumophila pneumonia. PLoS One. 2013;8(4):e61036.

44. Schalk JA, Docters van Leeuwen AE, Lodder WJ, de Man H, Euser S, den Boer JW, de Roda Husman AM. isolation of Legionella pneumophila from pluvial floods by amoebal coculture. Appl Environ Microbiol 2012, 78(12):4519-4521.

45. Hicks LA, Rose CE, Fields BS, Drees ML, Engel JP, Jenkins PR, Rouse BS, Blythe D, Khalifah AP, Feikin DR, et al. Increased rainfall is associated with increased risk for legionellosis. Epidemiol Infect. 2007;135(5):811-7.

46. Conza L, Casati S, Limoni C, Gaia V. Meteorological factors and risk of community-acquired Legionnaires' disease in Switzerland: an epidemiological study. BMJ Open. 2013;3:3.

47. Fisman DN, Lim S, Wellenius GA, Johnson C, Britz P, Gaskins M, Maher J, Mittleman MA, Spain CV, Haas CN, et al. It's not the heat, it's the humidity: wet weather increases legionellosis risk in the greater Philadelphia metropolitan area. J Infect Dis. 2005;192(12):2066-73.

48. U.S. Environmental Protection Agency. National Primary Drinking Water Regulations. 2009, EPA 816-F-09-004.

49. Tinker SC, Moe CL, Klein M, Flanders WD, Uber J, Amirtharajah A, Singer $\mathrm{P}$ Tolbert PE. Drinking water turbidity and emergency department visits for gastrointestinal illness in Atlanta, 1993-2004. J Expo Sci Environ Epidemiol. 2010;20(1):19-28.

50. Hsieh JL, Nguyen TQ, Matte T, Ito K. Drinking water turbidity and emergency department visits for gastrointestinal illness in new York City, 2002-2009. PLoS One. 2015:10(4):e0125071.

51. Mann AG, Tam CC, Higgins CD, Rodrigues LC. The association between drinking water turbidity and gastrointestinal illness: a systematic review. BMC Public Health. 2007;7(1):256.

52. World Health Organization. Cyanobacterial toxins: Microcystin-LR in Drinking-water. 2003

53. Michigan Department of Environmental Quality. Current State of Harmful Algal Bloom Impacts on Michigan Drinking Water Supplies. 2014.

54. Brzezińska A, Zawilski M, Sakson G. Assessment of pollutant load emission from combined sewer overflows based on the online monitoring. Environ Monit Assess. 2016;188(9):1-10.

55. Madoux-Humery A-S, Dorner S, Sauvé S, Aboulfadl K, Galarneau M, Servais P, Prévost M. Temporal variability of combined sewer overflow contaminants: evaluation of wastewater micropollutants as tracers of fecal contamination. Water Res. 2013;47(13):4370-82.

56. Holeton C, Chambers PA, Grace L. Wastewater release and its impacts on Canadian waters. Can J Fish Aquat Sci. 2011;68(10):1836-59.
57. Passerat J, Ouattara NK, Mouchel J-M, Rocher V, Servais P. Impact of an intense combined sewer overflow event on the microbiological water quality of the Seine River. Water Res. 2011;45(2):893-903.

58. Wade TJ, Sandhu SK, Levy D, Lee S, LeChevallier MW, Katz L, Colford JM Jr. Did a severe flood in the Midwest cause an increase in the incidence of gastrointestinal symptoms? Am J Epidemiol. 2004;159(4):398-405.

59. Wade TJ, Lin CJ, Jagai JS, Hilborn ED. Flooding and emergency room visits for gastrointestinal illness in Massachusetts: a case-crossover study. PLoS One. 2014:9(10):e110474

60. World Health Organization. 2012. Flooding and communicable diseases fact sheet. Available: http://www.who.int/hac/techguidance/ems/flood_cds/en/ [Accessed 1 Aug 2017].

61. Centers for Disease Control and Prevention. Mortality Data from the National Vital Statistics System; 1989. p. 119-23.

62. Division for Vital Records and Health Statistics. Michigan Population Trends by Race, 1990-2015. 2016.

63. Cameron L, Ferguson A, Walker R, Brown D, Briley L. Climate and Health Adaptation Profile Report: Building Resilience Against Climate Effects on Michigan's Health. Lansing: Michigan Department of Health and Human Services (MDHSS); 2015.

64. Levy MC, Collender PA, Remais JV, Carlton EJ, Chang HH, Strickland MJ, Eisenberg JNS. Spatiotemporal error in rainfall data: consequences for epidemiologic analysis of waterborne diseases; 2019.

65. Arbuthnott K, Hajat S, Heaviside C, Vardoulakis S. Changes in population susceptibility to heat and cold over time: assessing adaptation to climate change. Environ Health. 2016;15(Suppl 1):33.

66. Nordio F, Zanobetti A, Colicino E, Kloog I, Schwartz J. Changing patterns of the temperature-mortality association by time and location in the US, and implications for climate change. Environ Int. 2015;81:80-6.

67. Bobb JF, Peng RD, Bell ML, Dominici F. Heat-related mortality and adaptation to heat in the United States. Environ Health Perspect. 2014;122(8):811-6.

68. Petkova EP, Gasparrini A, Kinney PL. Heat and mortality in new York City since the beginning of the 20th century. Epidemiology. 2014;25(4):554-60.

69. U.S. Census Bureau. 2016. QuickFacts. Available: https://www.census.gov/ quickfacts/fact/table/RI,MI,US/PST045216 [Accessed 27 July 2017].

70. Jagai JS, DeFlorio-Barker S, Lin CJ, Hilborn ED, Wade TJ. Sanitary sewer overflows and emergency room visits for gastrointestinal illness: analysis of Massachusetts data, 2006-2007. Environ Health Perspect. 2017:125(11):117007.

71. Mirel LB, Carper K. Medical expenditure panel survey statistical brief \#429: trends in health care expenditures for the elderly, age 65 and older: 2001, 2006 and 2011: Quality AfHRa; 2014.

72. National Center for Health Statistics, U.S. Centers for Disease Control and Prevention. Health, United States, 2016: With Chartbook on Long-term Trends in Health. Hyattsville; 2017.

73. Moore BJ, Stocks C, Owens PL. Trends in Emergency Department Visits, 2006-2014; 2017.

74. Chang $\mathrm{HH}$, Zhou J, Fuentes M. Impact of climate change on ambient ozone level and mortality in southeastern United States. Int J Environ Res Public Health. 2010;7(7):2866-80.

75. Sheffield PE, Knowlton K, Carr JL, Kinney PL. Modeling of regional climate change effects on ground-level ozone and childhood asthma. Am J Prev Med. 2011;41(3):251-7 quiz A253.

76. Winquist A, Grundstein A, Chang HH, Hess J, Sarnat SE. Warm season temperatures and emergency department visits in Atlanta, Georgia. Environ Res. 2016;147:314-23.

77. Li S, Baker PJ, Jalaludin BB, Guo Y, Marks GB, Denison LS, Williams GM. Are childrens asthmatic symptoms related to ambient temperature? A panel study in Australia. Environ Res. 2014;133:239-45.

78. $\mathrm{Xu} \mathrm{Z}, \mathrm{Hu}$ W, Su H, Turner LR, Ye X, Wang J, Tong S. Extreme temperatures and paediatric emergency department admissions. J Epidemiol Community Health. 2014;68(4):304-11.

79. Lin S, Luo M, Walker RJ, Liu X, Hwang SA, Chinery R. Extreme high temperatures and hospital admissions for respiratory and cardiovascular diseases. Epidemiology. 2009;20(5):738-46.

80. Mireku N, Wang Y, Ager J, Reddy RC, Baptist AP. Changes in weather and the effects on pediatric asthma exacerbations. Ann Allergy Asthma Immunol. 2009;103(3):220-4.

81. MDHSS: Michigan Department of Health and Human Services (MDHHS), health indicators and risk estimates by Community Health Assessment Regions \& Local Health Departments, state of Michigan, selected tables, Michigan behavioral risk factor survey, 2011-2013. 2014, 
82. Strand $L B$, Barnett $A G$, Tong $S$. The influence of season and ambient temperature on birth outcomes: a review of the epidemiological literature. Environ Res. 2011;111(3):451-62.

83. Carolan-Olah M, Frankowska D. High environmental temperature and preterm birth: a review of the evidence. Midwifery. 2014;30(1):50-9.

84. Mathew S, Mathur D, Chang AB, McDonald E, Singh GR, Nur D, Gerritsen R. Examining the Effects of Ambient Temperature on Pre-Term Birth in Central Australia. Int J Environ Res Public Health. 2017;14:2.

85. Basu $R$, Chen $H$, Li DK, Avalos LA. The impact of maternal factors on the association between temperature and preterm delivery. Environ Res. 2017; 154:109-14.

86. Avalos LA, Chen H, Li DK, Basu R. The impact of high apparent temperature on spontaneous preterm delivery: a case-crossover study. Environ Health. 2017;16:5.

87. Schifano P, Asta F, Dadvand P, Davoli M, Basagana X, Michelozzi P. Heat and air pollution exposure as triggers of delivery: a survival analysis of population-based pregnancy cohorts in Rome and Barcelona. Environ Int. 2016;88:153-9.

88. He JR, Liu Y, Xia XY, Ma WJ, Lin HL, Kan HD, Lu JH, Feng Q, Mo WJ, Wang P, et al. Ambient temperature and the risk of preterm birth in Guangzhou, China (2001-2011). Environ Health Perspect. 2016;124(7):1100-6.

89. Ha S, Liu D, Zhu Y, Kim SS, Sherman S, Mendola P. Ambient temperature and early delivery of singleton pregnancies. Environ Health Perspect. 2016.

90. Basu R, Sarovar V, Malig BJ. Association between high ambient temperature and risk of stillbirth in California. Am J Epidemiol. 2016;183(10):894-901.

91. Arroyo V, Diaz J, Ortiz C, Carmona R, Saez M, Linares C. Short term effect of air pollution, noise and heat waves on preterm births in Madrid (Spain). Environ Res. 2016;145:162-8.

92. He JR, Liu Y, Xia XY, Ma WJ, Lin HL, Kan HD, Lu JH, Feng Q, Mo WJ, Wang P, et al. Ambient Temperature and the Risk of Preterm Birth in Guangzhou, China (2001-2011). Environ Health Perspect:2015.

93. Vicedo-Cabrera AM, Iniguez C, Barona C, Ballester F. Exposure to elevated temperatures and risk of preterm birth in Valencia, Spain. Environ Res. 2014; 134c:210-7.

94. Auger N, Fraser WD, Smargiassi A, Kosatsky T. Ambient heat and sudden infant death: a case-crossover study spanning 30 years in Montreal, Canada. Environ Health Perspect. 2015:123(7):712-6.

95. March of Dimes. 2015. Quick Facts: Preterm Birth: Detroit. Available: http:// www.marchofdimes.org/PeriStats/ViewTopic.aspx?reg=2622000\&top=3\&lev= 0\&slev=5 [Accessed 15 Sept 2015].

96. Basu R, Gavin L, Pearson D, Ebisu K, Malig B. Examining the association between apparent temperature and mental health-related emergency room visits in California. Am J Epidemiol. 2018;187(4):726-35.

97. Otte Im Kampe E, Kovats S, Hajat S. Impact of high ambient temperature on unintentional injuries in high-income countries: a narrative systematic literature review. BMJ Open. 2016;6(2):e010399.

98. Romero-Lankao P, Smith JB, Davidson DJ, Diffenbaugh NS, Kinney PL, Kirshen P, Kovacs P, Villers Ruiz L. North America. Cambridge, United Kingdom and New York, NY, USA; 2014. p. 1439-98.

99. Vanos JK. Children's health and vulnerability in outdoor microclimates: a comprehensive review. Environ Int. 2015;76:1-15.

100. Mead PS, Slutsker L, Dietz V, McCaig LF, Bresee JS, Shapiro C, Griffin PM, Tauxe RV. Food-related illness and death in the United States. Emerg Infect Dis. 1999;5(5):607-25.

101. Raftery AE, Zimmer A, Frierson DMW, Startz R, Liu P. Less than $2^{\circ} \mathrm{C}$ warming by 2100 unlikely. Nat Clim Chang. 2017;7:637.

102. National Climatic Data Center. 2010. Integrated Surface Database Lite. Available: http://www.ncdc.noaa.gov/oa/climate/isd/index.php [Accessed July 2010].

103. Bierwagen BG, Theobald DM, Pyke CR, Choate A, Groth P, Thomas JV, Morefield P. National housing and impervious surface scenarios for integrated climate impact assessments. Proc Natl Acad Sci. 2010;107:49.

104. Steenland K, Armstrong B. An overview of methods for calculating the burden of disease due to specific risk factors. Epidemiology. 2006;17(5):512-9.

105. U.S. Environmental Protection Agency. 2015. Integrated Climate and LandUse Scenarios. Available: http://www.epa.gov/iclus [Accessed 18 Sept 2015].

\section{Ready to submit your research? Choose BMC and benefit from:}

- fast, convenient online submission

- thorough peer review by experienced researchers in your field

- rapid publication on acceptance

- support for research data, including large and complex data types

- gold Open Access which fosters wider collaboration and increased citations

- maximum visibility for your research: over $100 \mathrm{M}$ website views per year

At BMC, research is always in progress.

Learn more biomedcentral.com/submissions 